\title{
Crustal deformation map for the 2011 off the Pacific coast of Tohoku Earthquake, detected by InSAR analysis combined with GEONET data
}

\author{
Tomokazu Kobayashi, Mikio Tobita, Takuya Nishimura, Akira Suzuki, Yuko Noguchi, and Masayuki Yamanaka \\ Geospatial Information Authority of Japan, Kitasato-1, Tsukuba, Ibaraki 305-0811, Japan
}

(Received April 7, 2011; Revised June 21, 2011; Accepted June 23, 2011; Online published September 27, 2011)

\begin{abstract}
Applying interferometric SAR (InSAR) analysis using ALOS/PALSAR data to a megathrust earthquake ( $M_{\mathrm{w}}$ 9.0) that ruptured off-shore of Tohoku, Japan, on 11 March, 2011, we succeeded in mapping a ground displacement distributed over $\sim 600 \mathrm{~km}$ range in the north-south orientation and $\sim 200 \mathrm{~km}$ range in the east-west orientation. A relative slant range lengthening of $\sim 4 \mathrm{~m}$ that is the largest displacement ever observed in Japan on InSAR records was detected at the tip of Oshika peninsula, consistent with GPS observations. The interferograms, calculated using quick but less accurate orbit data, are contaminated by long-wavelength noise, preventing us from measuring the correct ground displacement. We demonstrate that an InSAR analysis incorporating GEONET data effectively reduces noise and enables the prompt and accurate mapping of the ground displacement. Additionally, a clear coseismic signal due to an inland earthquake in northern Ibaraki on 19 March, $2011\left(M_{\mathrm{j}} 6.1\right)$ was also detected. Our preferred fault model assuming two segments shows a nearly pure normal fault motion with a west-dipping fault plane. The $\Delta \mathrm{CFF}$ calculation suggests that the $M_{\mathrm{w}} 9.0$ main shock promoted the $M_{\mathrm{j}} 6.1$ event. Key words: The 2011 Tohoku earthquake $\left(M_{\mathrm{w}} 9.0\right)$, InSAR, crustal deformation, northern Ibaraki earthquake $\left(M_{\mathrm{j}} 6.1\right)$.
\end{abstract}

\section{Introduction}

A megathrust earthquake with a moment magnitude $\left(M_{\mathrm{w}}\right)$ of 9.0 occurred on 11 March, 2011 (JST), rupturing the plate boundary to the east off northeastern Japan. Nationwide GPS continuous observation sites, termed GEONET (GPS Earth Observation Network System), recorded widely distributed ground displacements, locally in excess of $5 \mathrm{~m}$ (Geospatial Information Authority of Japan (GSI), 2011a).

Satellite synthetic aperture radar (SAR) data can provide detailed and spatially comprehensive ground information and an interferometric SAR (InSAR) enables us to measure ground deformation with high precision (e.g., Massonnet and Feigl, 1998; Bürgmann et al., 2000). One of the advantages of InSAR observation is that it can map vast ground displacement. One ALOS/PALSAR image used in this study covers an area approximately 70 by $70 \mathrm{~km}$ wide, which is helpful in grasping the spatial extent of crustal deformation. An additional advantage is that local crustal deformation can be monitored and detected. Although GPS sites (GEONET) are densely deployed with an average placement interval of $\sim 20-30 \mathrm{~km}$, it remains difficult to obtain high quality displacement data for small to moderate-sized earthquakes/volcanic activities, impeding detailed analysis of the source properties, such as fault

Copyright (C) The Society of Geomagnetism and Earth, Planetary and Space Sciences (SGEPSS); The Seismological Society of Japan; The Volcanological Society of Japan; The Geodetic Society of Japan; The Japanese Society for Planetary Sciences; TERRAPUB.

doi:10.5047/eps.2011.06.043 modeling. Alternatively, the ground resolution of SAR data (PALSAR) is $\sim 10 \mathrm{~m}$, so the InSAR observation works well to monitor and detect small to moderate-sized ground deformation anomalies over a large area.

We conducted an InSAR analysis of the 2011 Tohoku earthquake using ALOS/PALSAR data and succeeded in mapping a wide spatial range ground displacement mainly due to the $M_{\mathrm{w}} 9.0$ event. The SAR observation for the earthquake has not yet been completed. As of this writing, the SAR images obtained so far do not cover the whole crustal deformation area. However, the InSAR results provide us with some new findings and we believe that they contribute to the understanding of the $M_{\mathrm{w}} 9.0$ event and other relevant events. The purpose of this paper is to rapidly report surface displacements detected from InSAR observation after the great earthquake. In this paper, we focus our discussion on the following two aspects of the interferogram: an extremely wide range crustal deformation caused by the $M_{\mathrm{w}} 9.0$ main shock and a local change associated with the induced inland earthquake with a JMA (Japan Meteorological Agency) magnitude $\left(M_{\mathrm{j}}\right)$ of 6.1 in northern Ibaraki.

\section{InSAR Analysis}

To reveal the crustal deformation due to the 2011 Tohoku earthquake, we collected ALOS/PALSAR images acquired before and after the $M_{\mathrm{w}} 9.0$ event. JAXA (The Japan Aerospace Exploration Agency) made urgent observations for the great earthquake on 15 March (path 401), 20 March (path 404), 21 March (path 55) and 1 April (path 402) with fine beam mode, and on 14 March (path 60) and 31 March 
(path 61) with ScanSAR mode, respectively. The ScanSAR mode can observe a wide range width of $\sim 350 \mathrm{~km}$, which is capable of monitoring the extremely vast crustal deformation field at once. However, the interferometric coherence of the obtained images was too low to detect ground displacements, which may have been the result of large perpendicular baselines $(\sim 2 \mathrm{~km}$ and $\sim 5 \mathrm{~km})$. Thus, we used the fine beam mode data for the interferometric analysis. Three ascending orbit data (paths 401, 402, and 404) and one descending orbit data (path 55) are available for the InSAR analysis as of this writing. Six to eight scenes were concatenated for each path to cover the crustal deformation area. We processed the ALOS/PALSAR data using GSISAR software (Fujiwara and Tobita, 1999; Fujiwara et al., 1999; Tobita et al., 1999; Tobita, 2003).

\section{Crustal Deformation Obtained from InSAR Analysis}

Figure 1 shows all the wrapped interferograms analyzed for each path. Interferograms with high coherence are obtained although there exist low coherence areas in and around mountainous areas, reflecting the effects of snow. We can identify many concentric roundish fringes around the epicenter of the $M_{\mathrm{w}} 9.0$ event all over northeastern Japan. The round shape pattern can be identified at the northern and western margins of the interferograms. The significant displacement is distributed over at least $\sim 600 \mathrm{~km}$ range in the north-south direction and $\sim 200 \mathrm{~km}$ range in the east-west direction. All data confirms a lengthening of the slant range. Approximately 34 fringes are counted from the northernmost part of Honshu Island to the tip of Oshika peninsula; equivalent to a relative slant range lengthening of $\sim 4.0 \mathrm{~m}$. The observed length change in the radar line of sight direction $(\Delta \mathrm{LOS})$ is the largest displacement ever observed in Japan using InSAR. At the corresponding location, a maximum displacement is observed in GEONET with a nearly eastward motion of $\sim 5.3 \mathrm{~m}$ (EW: $5.1 \mathrm{~m} / \mathrm{NS}:-1.5 \mathrm{~m}$ ) and a subsidence of $\sim 1.2$ m (GEONET: 960550) (Fig. 1). The relative $\Delta$ LOS with respect to the northernmost part of Honshu (we use 020897 as the reference site) is $\sim 3.8 \mathrm{~m}$. The InSAR result agrees well with the GPS observations.

There still remains a discrepancy of $\sim 20 \mathrm{~cm}$ between the two. A possible cause of the remaining discrepancy is postseismic deformation (GSI, 2011b), attributed to a difference of observation date between the GPS (960550) and the InSAR measurements. The 960550 was unavailable due to the devastating tsunamis, so the above-mentioned displacement is an almost pure coseismic displacement. To confirm an effect of post-seismic deformation, we investigated the data at 960549 site, which is located $\sim 30 \mathrm{~km}$ west-northwest from 960550 and was still operable. At the site, a post-seismic displacement equivalent to $\Delta \mathrm{LOS}$ of $\sim 13 \mathrm{~cm}$ is measured until 31 March. Considering the effect of post-seismic deformation, the excess $\triangle \mathrm{LOS}$ of InSAR compared to the GPS measurement seems to be comparable. We additionally confirmed whether or not the discrepancy results from the accuracy of InSAR measurement. A difference between the GPS-observed $\triangle \mathrm{LOS}$ and the corresponding $\triangle \mathrm{LOS}$ in the interferogram, which is evaluated using the data during

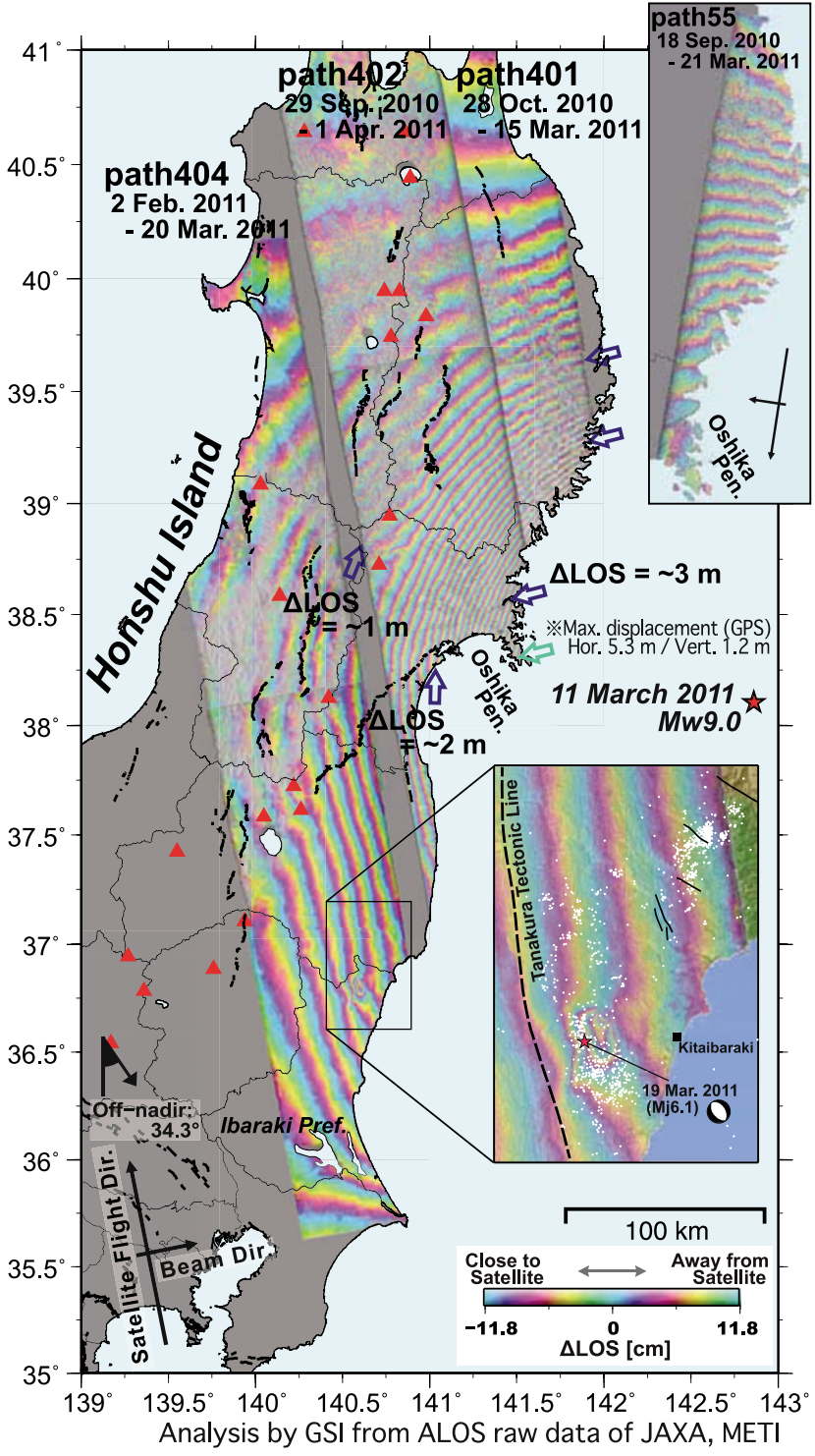

Fig. 1. Compilation of GPS-corrected interferograms derived from ALOS/PALSAR images. The red star is the epicenter of the 2011 Tohoku earthquake. Active fault traces and volcanoes are indicated by thick black lines and red triangles, respectively. Thin black lines are prefectural boundaries. Precise orbit data are used for all the interferograms. An inset at the bottom right focuses on the crustal deformation due to the northern Ibaraki earthquake $\left(M_{\mathrm{j}} 6.1\right)$. White dots indicate earthquakes shallower than $30 \mathrm{~km}$, which occurred from 11 March to 4 April. The beach ball diagram in the inset is from NIED (National Research Institute for Earth Science and Disaster Prevention) Earthquake Mechanism Search (http://www.fnet.bosai.go.jp/event/search.php?LANG=en).

the same observation period, is $\sim 8.2 \mathrm{~cm}$ at the maximum (RMS (root mean square) residual: $\sim 2.2 \mathrm{~cm}$ ) for path 402 . Thus, the discrepancy significantly exceeds the uncertainty of InSAR measurement.

Several GEONET sites along the coast ceased operation because of devastating tsunamis, so we have not obtained the spatially detailed ground deformation along the coast due to the sparseness of observation density (GSI, 2011a). However, the InSAR results successfully detected the spatially comprehensive ground deformation with high displacement gradients, showing that the coastal zone widely deformed with displacements of meters. 
(a)

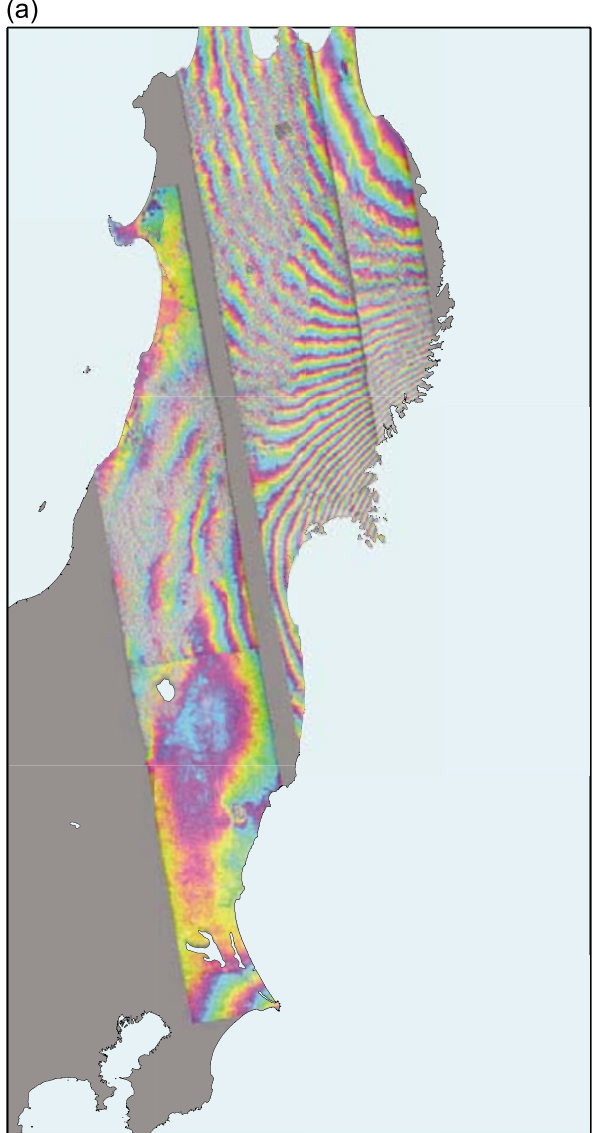

(b)

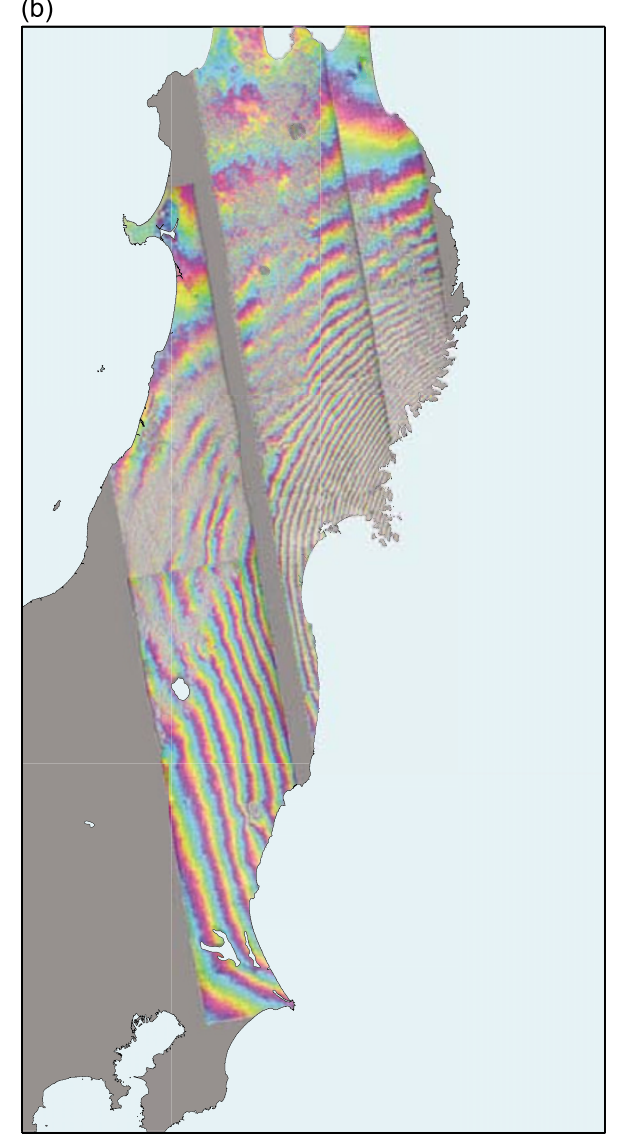

Fig. 2. (a) Interferograms with no GPS-correction using RARR (Range And Range Rate) orbit data. For path 404, orbital fringes are removed using re-estimated satellite orbit information. (b) GPS-corrected interferograms using RARR orbit data.

There are some reports that seismic and volcanic activities are enhanced after the great earthquake maybe due to static/dynamic stress perturbations (e.g., Koyama, 2002). Northeastern Japan is one of the most tectonically active regions, having many active faults and volcanoes. Active fault traces and active volcanoes are plotted on the interferograms in Fig. 1, represented by thick black lines and red triangles, respectively. Comparing the locations and the corresponding $\triangle$ LOS fields, no remarkable anomalies have been recognized along the faults or in close proximity to the volcanoes.

\section{GPS-combined InSAR Analysis}

For a devastating earthquake disaster, it is vital to map and monitor the ground displacement as promptly as possible. Interferograms shown in Fig. 1 are obtained using precise orbit information data. This orbit information provides a high accuracy of $40 \mathrm{~cm} \mathrm{(3 \sigma )} \mathrm{(Shimada,} \mathrm{2010),} \mathrm{which} \mathrm{ben-}$ efits InSAR analysis by reducing orbital fringes produced as a result of using the wrong satellite positions. However, the precise orbit information is distributed a few days after an image acquisition at the earliest, so the delay is an obstacle for prompt monitoring of ground displacement. The RARR (Range And Range Rate) information is less accurate but is quickly distributed (usually within a few hours after an image acquisition). Figure 2(a) shows interferograms analyzed using RARR orbit data. The interferograms include non-negligible long-wavelength phase changes, which are substantial in the far field. In the north of Honshu, the eastern part appears to have moved more toward the satellite than the western part, which is not the crustal deformation pattern predicted from the slip mechanism of the $M_{\mathrm{w}} 9.0$ event. We thus made a correction to the "quick" interferograms using GEONET data to suppress the longwavelength noise, in which the difference between $\triangle$ LOSs of the quick interferogram and those based on GEONET data is approximated by a bilinear function and the original interferogram is corrected by subtracting the bilinear function (Tobita et al., 2005). For the correction, we used F3 and R3 solution data corresponding to the observation dates of master and slave images, respectively (Nakagawa et al., 2009); the former is the most accurate but is available within about two weeks latency, while the latter is less accurate but is more rapidly distributed within a latency of two days. A total of 169 GPS stations were used in the correction. Figure 2(b) shows the GPS-corrected interferograms. Through the GPS-correction, the fringes between neighboring paths are smoothly connected and the crustal deformation is reasonably mapped all over the observed area. The RMS residuals of $\triangle \mathrm{LOS}$ at the GPS sites between observations and calculations are $84.2 \mathrm{~cm}$ and $9.9 \mathrm{~cm}$ for before and after the GPS correction, respectively. The results suggest that a correction for long-wavelength noise using GPS data is indispensable for the prompt and accurate mapping of ground displacement using RARR orbit data.

Using the precise orbit data, the unnatural fringes are 
Table 1. Fault parameters of our preferred model. We define the location of each fault as the center. The unit of length, width, and depth is in kilometers. Dip, strike and rake are in degrees, and slip is in meters. In the lowest row, the fault parameters from the CMT solution (NIED Earthquake Mechanism Search (http://www.fnet.bosai.go.jp/event/search.php?LANG=en)) are listed for comparison.

\begin{tabular}{cccccccccccc}
\hline Fault & Longitude & Latitude & Depth & Length & Width & Strike & Dip & Rake & Slip & $M_{\mathrm{w}}$ \\
\hline 1 & 140.605 & 36.793 & 4.0 & 6.9 & 3.0 & 157.0 & 62.5 & -107.1 & 1.5 & 5.9 & \\
2 & 140.609 & 36.819 & 0.8 & 2.8 & 1.4 & 141.6 & 69.4 & -85.7 & 1.2 & 5.4 \\
\hline CMT & 140.572 & 36.784 & 5.4 & - & - & $141 / 327$ & $48 / 42$ & $-94 /-86$ & - & 5.8
\end{tabular}

considerably reduced. However, the unnatural deformation pattern showing that the eastern part moves more towards the satellite than the western part still slightly remained in the northernmost part of Honshu, which may be attributed to an ionosphere disturbance. We further made a GPS-correction to the interferograms using precise orbit data (Fig. 1) to suppress the noises and to map the ground displacement more correctly, although there is no crucial difference between the result with GPS correction and that without correction.

\section{Inland Earthquake of Northern Ibaraki $\left(M_{\mathrm{j}}\right.$ 6.1)}

Following the $M_{\mathrm{w}} 9.0$ event, many inland crustal earthquakes occurred in addition to aftershocks on the plate boundary. Northern Ibaraki is one of the regions where the seismicity drastically changed from a quiescent stage to an active stage (Fig. 1). In the seismically activated region, a clear coseismic deformation due to an inland earthquake that occurred on 19 March 2011, with $M_{\mathrm{j}} 6.1$ was detected (Fig. 1). No active fault is known in the source region. The most concentrated crustal deformation is located $\sim 10 \mathrm{~km}$ west of the city of Kitaibaraki, with a maximum slant range lengthening of $\sim 40 \mathrm{~cm}$ (Fig. 3(a)). A displacement discontinuity with a relative displacement exceeding $30 \mathrm{~cm}$ is recognized and featured with blue arrows in Fig. 3(a), probably suggesting that a rather shallow slip occurred. On the basis of the interferogram data, we constructed a fault model under an assumption of a rectangular fault with a uniform slip in elastic half-space (Okada, 1992). To pick up the ground displacement corresponding to the $M_{\mathrm{j}} 6.1$ event, we removed the long-wavelength ground displacement due to the $M_{\mathrm{w}} 9.0$ by applying a bilinear correction for flattening. For the modeling, we assumed both a one-segment and a two-segment model. We applied a simulated annealing method for searching the optimal fault parameters (e.g., Cervelli et al., 2001). As a result, we adopted the two-segment fault model as the optimal solution because the one-segment model is not able to account for the local intensive displacement near the discontinuity area. Additionally, the AIC (Akaike's information criterion) (Akaike, 1974) values support the two-segment model (AIC $=-754.8)$ rather than the one-segment model (AIC $=-572.3)$. The two-segment model is able to reconcile the observations well (Figs. 3(b) and 3(c)). The estimated fault parameters are listed in Table 1. Our fault model shows (1) west-dipping fault planes with dip angles of $60-70^{\circ}$, (2) NNW-SSE (NW-SE) strike direction, (3) nearly pure normal fault motions, and (4) a shallow local slip (a depth of upper fault edge of $0.2 \mathrm{~km}$ ).

The $M_{\mathrm{j}} 6.1$ earthquake occurred at the east of the south- (a)

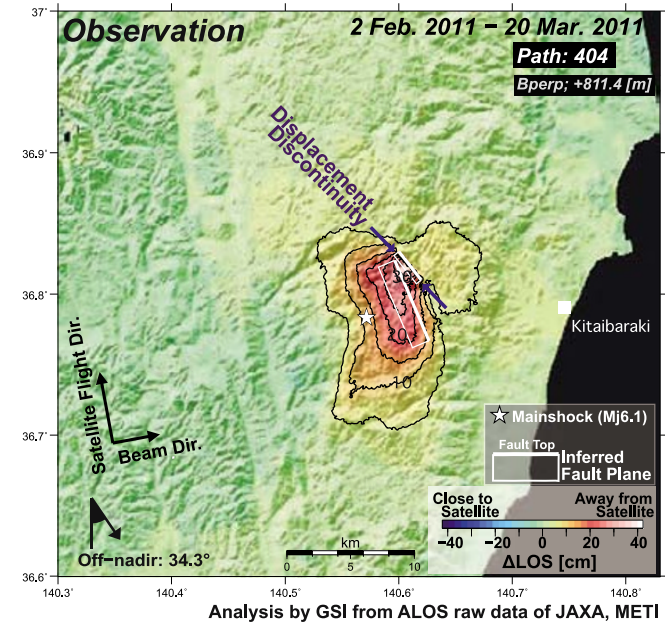

(b)

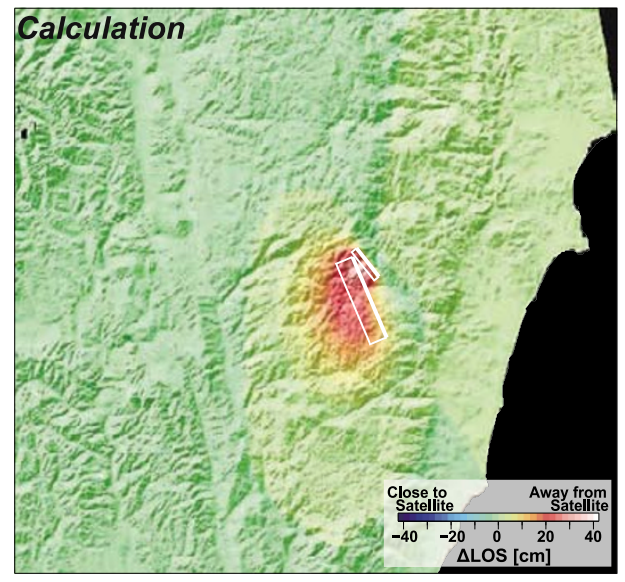

(c)

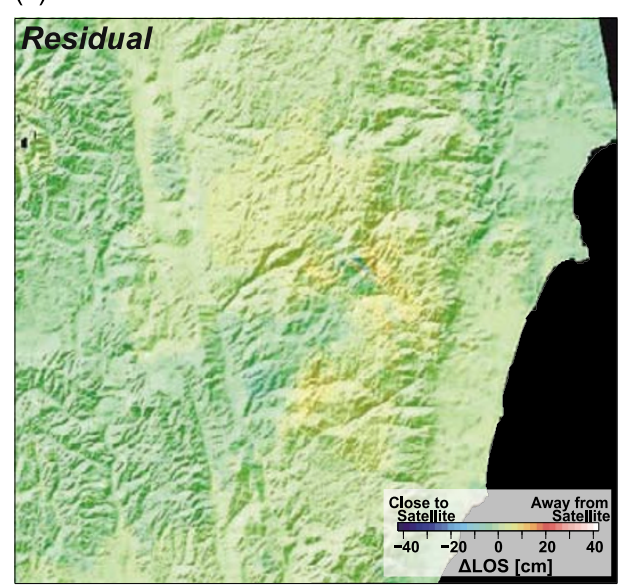

Fig. 3. (a) Observed $\triangle \mathrm{LOS}$ for the earthquake on 19 March 2011 at northern Ibaraki. (b) Calculated $\triangle$ LOS. (c) Residual between the observations (a) and the calculations (b). White frames indicate surface projections of the faults proposed in this study. Thick white lines stand for the upper edges. 
ern Tanakura tectonic line. The region had been seismically inactive but after the $M_{\mathrm{w}} 9.0$ event the seismicity became active. It is striking that many of the earthquakes are of a normal fault type, which is not a typical type for the region of reverse/strike-slip motions, reflecting the plate loading in an east-west direction. The timing of the seismicity activation suggests a possible causal relationship with the $M_{\mathrm{w}} 9.0$ event. The crust along the coastal northeastern zone of Japan is considered to be subjected to a strong extensional stress change due to the reverse fault slip of the $M_{\mathrm{w}} 9.0$ event and the subsequent afterslip (GSI, 2011b), which presumably culminates in the promotion of a normal-fault slip. To test the idea quantitatively, we evaluated $\triangle \mathrm{CFF}$ at a depth of $5 \mathrm{~km}$ with an effective coefficient of friction of 0.4 and a rigidity of $30 \mathrm{GPa}$ (Stein et al., 1994). Assuming fault \#1 (Table 1) is a receiver fault, the $\triangle \mathrm{CFF}$ calculated using the fault model proposed by GSI (GSI, 2011c) has a positive sign with a value of $0.68 \mathrm{MPa}$. We evaluated the stability of our stress change pattern for an effective coefficient of friction from 0.2 to 0.8 , and confirmed that in all cases the $\triangle \mathrm{CFF}$ values have a positive value $(0.56$ to $0.92 \mathrm{MPa})$. The $\triangle \mathrm{CFF}$ agrees that the static stress change caused by the $M_{\mathrm{w}} 9.0$ event facilitated the occurrence of the $M_{\mathrm{j}} 6.1$ event.

\section{Concluding Remarks}

We applied InSAR analysis using ALOS/PALSAR data for the 2011 Tohoku earthquake. The following conclusions are obtained from the analysis:

1) We successfully mapped an extremely wide range crustal deformation caused by the $M_{\mathrm{w}} 9.0$ main shock, with a relative slant range lengthening of $\sim 4 \mathrm{~m}$ at the tip of Oshika peninsula.

2) We demonstrated that an InSAR analysis incorporating GEONET data effectively works to reduce the noise, and enables prompt and accurate mapping of ground displacement.

3) We detected a coseismic signal due to an inland earthquake at northern Ibaraki $\left(M_{\mathrm{j}} 6.1\right)$. Our fault model assuming two segments shows a nearly pure normal fault motion with west-dipping fault plane.

4) The $\triangle$ CFF calculation suggests that the $M_{\mathrm{w}} 9.0$ event promoted the occurrence of the $M_{\mathrm{j}} 6.1$ event.

Acknowledgments. PALSAR data was provided from Earthquake Working Group under a cooperative research contract with JAXA (Japan Aerospace Exploration Agency). The ownership of PALSAR data belongs to JAXA and METI (Ministry of Economy, Trade and Industry). We used GMT (Generic Mapping Tools) provided by Wessel and Smith (1998) for constructing the figures. We thank two anonymous reviewers and the editor (Prof. Yomogida) for their helpful comments to improve our manuscript.

\section{References}

Akaike, H., A new look at the statistical model identification, IEEE Trans. Auto. Control, 19, 716-723, 1974.

Bürgmann, R., P. A. Rosen, and E. J. Fielding, Synthetic aperture radar interferometry to measure Earth's surface topography and its deformation, Ann. Rev. Earth Planet. Sci., 28, 169-209, 2000.

Cervelli, P., M. H. Murray, P. Segall, Y. Aoki, and T. Kato, Estimating source parameters from deformation data, with an application to the March 1997 earthquake swarm off the Izu Peninsula, Japan, J. Geophys. Res., 106, 11217-11237, 2001.

Fujiwara, S. and M. Tobita, SAR interferometry techniques for precise surface change detection, J. Geod. Soc. Jpn., 45, 283-295, 1999 (in Japanese with English abstract).

Fujiwara, S., M. Tobita, M. Murakami, H. Nakagawa, and P. A. Rosen, Baseline determination and correction of atmospheric delay induced by topography of SAR interferometry for precise surface change detection, J. Geod. Soc. Jpn., 45, 315-325, 1999 (in Japanese with English abstract).

Geospatial Information Authority of Japan, The 2011 off the Pacific coast of Tohoku Earthquake: Coseismic slip distribution model (preliminary), http://www.gsi.go.jp/cais/topic110315-index-e.html, 2011a.

Geospatial Information Authority of Japan, The 2011 off the Pacific coast of Tohoku Earthquake: Postseismic slip distribution model (preliminary), http://www.gsi.go.jp/cais/topic110315.2-index-e.html, 2011b.

Geospatial Information Authority of Japan, The 2011 off the Pacific coast of Tohoku Earthquake: Crustal deformation and fault model (preliminary), http://www.gsi.go.jp/cais/topic110313-index-e.html, 2011c.

Koyama, M., Mechanical coupling between volcanic unrests and large earthquakes: A review of examples and mechanisms, J. Geogr., 111, 222-232, 2002 (in Japanese with English abstract).

Massonnet, D. and K. L. Feigl, Radar interferometry and its application to changes in the earth's surface, Rev. Geophys., 36, 441-500, 1998.

Nakagawa, H., T. Toyofuku, K. Kotani, B. Miyahara, C. Iwashita, S. Kawamoto, Y. Hatanaka, H. Munekane, M. Ishimoto, T. Yutsudo, N. Ishikura, and Y. Sugawara, Development and Validation of GEONET New Analysis Strategy (Version 4), Bull. GSI, 118, 1-8, 2009 (in Japanese).

Okada, Y., Internal deformation due to shear and tensile faults in a half space, Bull. Seismol. Soc. Am., 82, 1018-1040, 1992.

Shimada, M., On the ALOS/PALSAR operational and interferometric aspects, J. Geod. Soc. Jpn., 56, 13-39, 2010 (in Japanese with English abstract).

Stein, R. S., G. C. P. King, and J. Lin, Stress triggering of the 1994 M=6.7 Northridge, California earthquake by its predecessors, Science, 265, 1432-1435, 1994.

Tobita, M., Development of SAR interferometry analysis and its application to crustal deformation study, J. Geod. Soc. Jpn., 49, 1-23, 2003 (in Japanese with English abstract).

Tobita, M., S. Fujiwara, M. Murakami, H. Nakagawa, and P. A. Rosen, Accurate offset estimation between two SLC images for SAR interferometry, J. Geod. Soc. Jpn., 45, 297-314, 1999 (in Japanese with English abstract).

Tobita, M., H. Munekane, S. Matsuzaka, M. Kato, H. Yarai, M. Murakami, S. Fujiwara, H. Nakagawa, and T. Ozawa, Studies on InSAR data processing technique, Bull. GSI, 106, 37-49, 2005 (in Japanese).

Wessel, P. and W. H. Smith, New, improved version of Generic Mapping Tools released, Eos Trans. AGU, 79, 579, 1998.

T. Kobayashi (e-mail: tkoba@gsi.go.jp), M. Tobita, T. Nishimura, A. Suzuki, Y. Noguchi, and M. Yamanaka 